\title{
¿Debe tenerse en cuenta la capacidad económica del sujeto obligado en la tipicidad del delito de omisión a la asistencia familiar?(*)
}

\section{Should the economic capacity of the debtor be taken into account in the prosecution of the crime of omission of family assistance?}

\author{
Renzo Antonio Vinelli Vereau ${ }^{(*)}$ \\ Payet, Rey, Cauvi, Pérez Abogados
}

Aitana Sifuentes Small $\left.{ }^{(\star \star *}\right)$

Universidad de Lima

\begin{abstract}
Resumen: En el presente artículo los autores desarrollan la figura de la obligación alimentaria reconocida en el ordenamiento civil peruano, la cual es analizada por el juez civil teniendo en consideración la capacidad económica del obligado. Frente a ello, se presenta el delito de omisión a la asistencia familiar, el cual se verifica con el incumplimiento de la obligación alimentaria de naturaleza civil. Sin embargo, al momento de dilucidar la existencia del delito, la jurisprudencia penal no ha optado por analizar el concepto de capacidad económica como elemento objetivo del delito, a diferencia del ordenamiento civil. En ese sentido, se discute la necesidad de incluir la solvencia económica del obligado en el análisis penal como un elemento del tipo.
\end{abstract}

Palabras clave: Derecho Penal - Obligación alimentaria - Capacidad económica Omisión a la asistencia familiar - Análisis del tipo - Perú

\begin{abstract}
In this paper, the authors discuss the maintenance obligation recognized by Peruvian civil laws, which the civil judge analyzes taking into account the economic capacity of the debtor. On the other hand, the Peruvian law typifies the crime of omission of family assistance, which is verified by the sole breach of the obligation by the debtor. However, criminal jurisprudence has not taken into account the concept of economic capacity as an objective element of this offence, unlike their civil counterpart. Thus, the authors discuss the need to include the economic capacity of the debtor in the analysis of the crime of omission of family assistance.
\end{abstract}

Keywords: Criminal Law - Maintenance obligation - Economic capacity - Omission of family assistance - Crime typification - Peru.

$\left(^{*}\right) \quad$ Nota del Editor: este artículo fue recibido el 1 de marzo de 2019 y su publicación fue aprobada el 4 de mayo de 2019.

${ }^{* *}$ Abogado por la Universidad de San Martín de Porres. Máster en Derecho penal por la Universidad de Sevilla. Abogado Senior del área penal de Payet, Rey, Cauvi, Pérez Abogados.

${ }^{(* *)}$ Estudiante de Derecho de la Universidad de Lima. 


\section{Introducción}

El presente trabajo académico pretende demostrar la necesidad que existe en la labor judicial penal en nuestro país de reconocer la capacidad económica del agente como un elemento objetivo en el delito de omisión a la asistencia familiar, previsto en el artículo 149 del Código Penal. La mencionada afirmación se sustentará en la aproximación que realiza el ordenamiento civil sobre la figura de obligación alimentaria sobre la cual se reconoce y se considera la capacidad del agente. Asimismo, y en atención a las semejanzas entre el delito de omisión a la asistencia familiar y el de desobediencia y resistencia a la autoridad, se denota cómo la jurisprudencia sí ha incluido la capacidad de cumplimiento del agente como elemento de aquel delito y no de este último.

En virtud de ello, la importancia aplicativa de fijar la capacidad económica como elemento objetivo para que se configure el delito de omisión a la asistencia familiar viene dada por establecer un criterio jurisprudencial para casos de esta naturaleza, resultando en la predictibilidad de las sentencias, así como obtener congruencia entre los enfoques del ordenamiento civil y penal.

El fenómeno de la omisión a la asistencia familiar generó que el legislador en aras de protección de un sector vulnerable de la sociedad tipificara en el capítulo Delitos contra la Familia diversos injustos penales en nuestro ordenamiento penal, siendo su manifestación más clara el injusto previsto en el artículo 149 del Código Penal.

Así como advertimos a diario, la judicatura civil en la que se encuentra la justicia de familia se encarga de velar por el cumplimiento de las prestaciones alimentarias, encontrándose sometida a una abundante carga procesal que muchas veces impide obtener un pronunciamiento para el alimentista dentro de un plazo razonable. Es más, en sede civil se ha creado un Registro de deudores alimentarios morosos establecido en la Ley 28970 , similar a las agencias de clasificación de riesgo crediticio, con el objeto de disuadir el incumplimiento de las obligaciones alimentarias.

En el presente trabajo queremos plantear como punto de análisis si la capacidad económica del sujeto obligado a brindar alimentos es un elemento que debe ser valorado por el juez penal al momento de realizar un juicio de tipicidad penal, o si dicho aspecto debe dilucidarse en sede civil; más aún cuando advertimos con claro estupor que se viene sancionando el delito de omisión a la asistencia familiar ante el simple incumplimiento de la pensión alimenticia como una criminalización de una deuda (Reyna 2017, 26) $)^{(1)}$ claramente proscrita por nuestro ordenamiento constitucional.
Como primera parte del presente trabajo analizaremos la teoría de los alimentos, definición legal de los mismos, el orden de prelación de los obligados frente al alimentista, para luego entrar al análisis de la tipicidad del delito de omisión a la asistencia familiar.

\section{Sobre la teoría de los alimentos}

La regulación de familia no se limita a establecer quiénes son parientes ni cuál es el verdadero significado de familia, lo que el sistema jurídico busca en sí es determinar los derechos y obligaciones de cada miembro del grupo familiar. La obligación alimentaria no solo abarca el deber de los padres con los hijos, o el deber de asistencia que existe entre cónyuges, sino que además se deben alimentos recíprocamente los ascendientes y descendientes, y los hermanos (Chávez 2017, 31-32).

Ahora bien, la obligación alimentaria es regulada por nuestro sistema jurídico, el cual establece que los padres deben proporcionar todo lo indispensable para el desarrollo de los hijos. Este deber se adquiere desde el momento de la concepción y aparentemente culminaría con la mayoría de edad; sin embargo, hay excepciones a la regla, como por ejemplo lo estipulado en el artículo 473 del Código Civil, que señala la obligación de pasar alimentos a aquellos hijos mayores de 18 años, solteros, que cursen estudios universitarios exitosos, pero que no cuenten con la capacidad de costear y satisfacer sus necesidades básicas; y también aquellos que, por incapacidad física o mental debidamente comprobada no puedan valerse por sí mismos ni puedan satisfacer lo indispensable para una buena calidad de vida.

La definición de alimentos se encuentra contenida en el artículo 472 del Código Civil de la siguiente manera:

"Se entiende por alimentos lo que es indispensable para el sustento, habitación, vestido y asistencia médica, según la situación y posibilidad de la familia.

(1) El autor considera que la tipificación del delito de omisión a la asistencia familiar, también llamado abandono familiar, en su consideración, es una mera criminología de deudas. 
Cuando el alimentista es menor de edad, los alimentos comprenden también su educación, instrucción y capacitación para el trabajo".

Asimismo, el artículo 92 del Código de los Niños y Adolescentes señala lo siguiente:

"Se considera alimentos, lo necesario para el sustento, habitación, vestido, educación, instrucción y capacitación para el trabajo, asistencia médica y recreación del niño o del adolescente. También los gastos del embarazo de la madre desde la concepción hasta la etapa de postparto (sic)".

Ante ello, debemos indicar que el origen del vocablo alimentos, proviene del latín alimentum o ablere, el cual significa nutrir, alimentar. Sin embargo, podemos decir que los alimentos implican más allá de la palabra propiamente dicha, en el sentido más extenso, debido a que es todo lo que nos ayuda a protegernos para poder vivir y desarrollarnos en forma digna (Chunga 2003) ${ }^{(2)}$.

Debemos recalcar que en el artículo 472 del Código Civil se indica que los alimentos deben ser proporcionados según la situación y posibilidad de la familia; ello quiere decir que si el niño está acostumbrado a un determinado estilo de vida, comodidades, entre otras cosas; el juez deberá fijar una cantidad o porcentaje por alimentos que deberá igualar la situación en la que se encuentra, siempre considerando el ingreso mensual de ambos padres, ya que los ambos tienen iguales derechos y por ende iguales obligaciones, primando el interés superior del niño en todo momento.

Como mencionamos anteriormente, la definición brindada en el Código Civil se complementa con el artículo 92 del Código del Niño y Adolescente, debido a que agrega, como parte de las necesidades del menor, los conceptos de recreación y gastos del embarazo de la madre desde la concepción hasta la etapa de postparto.

Ante ello, como bien sostiene Carmen Chunga Chávez, en cuanto al concepto de recreación, ello se trata de un aspecto necesario e importante para el desarrollo integral de la persona, más aún en el crecimiento del niño y adolescente; sin embargo, establece que el aspecto novedoso versa en los gastos que realiza la madre durante el embarazo y la etapa de post parto, partiendo de un principio consagrado en nuestra Constitución, y es que la vida empieza desde la concepción, teniendo protección legal desde dicha etapa.

Sobre el particular, el artículo 474 establece la obligación recíproca de prestar alimentos entre los cónyuges, los ascendientes y descendientes, y los hermanos. Somos de la opinión de que los cónyuges tienen el derecho-deber de mutua asistencia, en virtud de su estado familiar; no obstante, la obligación recíproca de darse alimentos deja de ser latente para hacerse exigible ante su incumplimiento. Para ello, el cónyuge afectado debe acreditar su estado de necesidad, la imposibilidad de atender su propia subsistencia, siendo esto un aspecto que motiva nuestro análisis de tipicidad penal del delito de omisión a la asistencia familiar.

En cuanto a la obligación recíproca entre ascendientes y descendientes, se extiende la obligación a todos los parientes en línea recta siguiendo el orden establecido en el artículo 475. Pues bien, los hijos sin excepción alguna tienen los mismos derechos, estando los padres en la obligación de brindar educación y alimentos, teniendo incluso vigente la obligación si el hijo tiene entre dieciocho y veintiocho años, y desee seguir estudios técnicos o universitarios con éxito, o si se encuentra en un estado de incapacidad física o mental (Hernández 2003).

Adicionalmente, entre hermanos existe la obligación recíproca, si el alimentista es menor de edad, en ambos casos, se incluye a los hermanos y medio hermanos tanto del padre, como de la madre, "porque la obligación alimentaria se encuentra reforzada en la solidaridad familiar" (Chávez 2017, 56).

Respecto al orden de prelación de los obligados alimentarios, ello se encuentra regulado en el artículo 475 del Código Civil, el cual regula el orden que el alimentista debe seguir y respetar al exigir la prestación.

El orden de prelación opera de la siguiente manera:

“a) Cónyuges: El artículo bajo comentario ha considerado como primer obligado al cónyuge, pese a no ser pariente, debido a la comunidad de vida económica y espiritual que nace con el matrimonio, la cual implica un deber de asistencia mutua, el cual incluye en su aspecto material a los alimentos.

En el orden sucesorio el cónyuge, pese a ser del tercer orden, concurre tanto con descendientes como con los ascendientes del primer y segundo orden sucesorio respectivamente. Podría decirse por ello

(2) El autor considera que la palabra "alimentos debe ser entendida en un plano no tan litera, más extenso, todo aquello que conlleva cubrir las necesidades básicas para el desarrollo integral de la persona. 
que siendo del primer orden es también el primero en obligación respecto de su cónyuge. (...)

b) Descendientes: En segundo lugar, en la prelación se encuentran los descendientes, siendo los obligados inmediatos los hijos y a falta de éstos o por su pobreza los otros descendientes.

c) Ascendientes: En tercer lugar, se encuentran los padres y demás ascendientes. En este caso el fundamento de la obligación del mismo modo que en los descendientes es el parentesco en línea recta.

d) Hermanos: Por último, se encuentran obligados los hermanos, parientes colaterales en segundo grado. (...)" (Hernández 2003).

Asimismo, debemos indicar cuáles son los criterios para fijar la obligación alimentaria, los mismos que se encuentran contenidos en el artículo 481 del Código Civil, el cual establece lo siguiente:

\section{"Artículo 481.-}

Los alimentos se regulan por el juez en proporción a las necesidades de quien los pide y a las posibilidades del que debe darlos, atendiendo además a las circunstancias personales de ambos, especialmente a las obligaciones a que se halle el sujeto deudor".

Pues bien, los alimentos deben ser determinados por el juzgador en proporción a las necesidades del alimentista, así como la persona que debe brindarlos. Ello quiere decir que la pensión puede ir variando de acuerdo a las circunstancias en las que se vea inmerso el alimentista y el alimentante(Morán 2003).

En efecto, debe tenerse en consideración al momento de fijar la pensión alimentaria los ingresos del alimentante, sin embargo, la jurisprudencia también establece diversos criterios para determinar la pensión de alimentos, los cuales se exponen en los párrafos siguientes:

“a) La potencialidad de trabajo de la parte demandante: Este supuesto está relacionado con las posibilidades económicas del alimentante y a las posibilidades que tiene para satisfacer necesidades básicas, su capacidad productiva y laboral (...).

b) La capacitación y especialización laboral del obligado: Esta igualmente relacionado con las posibilidades económicas del alimentante, aunque está más dirigido al análisis de su preparación y capacitación académica y laboral que le permite acceder a una mejor posición y situación económica.

c) Realización de viajes al extranjero por el obligado a dar alimentos: Otro elemento determinado son los viajes constantes del alimentante al exterior, considerándose tales supuestos como indicadores de una situación económica acomodada, dado el carácter oneroso de tales viajes.

d) Las boletas de remuneraciones del obligado: Refiere al mecanismo probatorio de las posibilidades económicas del alimentante.

e) Inaplicación de un convenio de alimentos preexistente: (...) Carece de validez cualquier convenio en el que se haya pactado el cumplimiento de los abonos de las pensiones alimenticias, prevaleciendo así el derecho del alimentario (...).

f) Revisión de las pensiones establecidas en sentencia judicial: no hay cosa juzgada en materia de alimentos: Puede variarse el monto determinado por sentencia judicial de la pensión de alimentos, así debe tenerse en cuenta que la existencia de una sentencia de alimentos no conlleva la aplicación del principio de cosa juzgada estando a la finalidad de asistencia que sustenta el derecho de alimentos (...).

g) Cambio de la pensión en porcentaje a monto fijo: La determinación del monto de la pensión puede ser establecida con base en un porcentaje de los ingresos del alimentante o en base a un monto fijo.

h) Variación de la pensión por el cambio de la moneda: Otro factor que sustenta la variación de la pensión alimenticia lo encontramos en la variación de la moneda nacional (...)" (Canales 2013, 76-83).

Dichos criterios se basan en la capacidad económica que ostenta el deudor alimentista, debido a que para fijar el monto de la pensión alimentaria este debe incluir todo aquello que demuestre un incremento o una disminución en el patrimonio del obligado, teniendo como base el principio de interés superior del niño.

Sin embargo, este monto fijado en una resolución judicial puede variar en virtud a situaciones como la pérdida o aumento de los ingresos mensuales del deudor alimentario, o el cambio de situación en la que puede encontrarse el acreedor de la pensión alimentaria.

Es por ello que debemos indicar que nuestro Código Civil establece en el artículo 482 criterios para el reajuste o variación de la pensión alimenticia: 
"Artículo 482.-

La pensión alimenticia se incrementa o reduce según el aumento o disminución que experimentan las necesidades del alimentista y las posibilidades del que debe prestarla. Cuando el monto de la pensión se hubiese fijado en un porcentaje de las remuneraciones del obligado, no es necesario nuevo juicio para reajustarla. Dicho reajuste se produce automáticamente según las variaciones de dichas remuneraciones".

Este artículo establece cuáles son las causas por las que la obligación alimentaria fijada puede aumentar o disminuir, siendo que, en efecto, al ser la prestación de alimentos una obligación de tracto sucesivo o cumplimiento periódico puede estar sujeta a diversas modificaciones durante su tiempo de vigencia (Morán 2003).

Adicionalmente, debemos tener en consideración que el mencionado artículo trata únicamente de las variaciones que puede experimentar la pensión alimentaria determinada a consecuencia de una modificación en el aspecto pasivo o la disminución patrimonial del deudor alimenticio, o en el aspecto activo o incremento de los ingresos del alimentista, siempre y cuando el cambio sea debidamente justificado.

Es menester indicar que nuestro sistema procesal indica que la variación en la pensión alimentaria tendrá vigencia recién a parir del día siguiente a la fecha de la notificación de la demanda en la que se solicita el aumento o disminución, siempre y cuando hubiesen sido aprobadas por resolución judicial (Morán 2003)(3).

Tal cual lo establece la Casación No.1371-96-Huánuco, de la siguiente manera:

Debido a la naturaleza del derecho alimentario, éste se encuentra sujeto a las variaciones que podrían ocurrir en el tiempo respecto al estado de necesidad de los beneficiados o a las posibilidades del obligado, por ello la ley autoriza a solicitar la modificación o la exoneración de la pensión alimenticia.

Una vez mencionados los criterios para fijar los alimentos y las variaciones que pueden sufrir debemos detallar las causales de exoneración de alimentos, detalladas en el artículo 483 del Código Civil de la forma siguiente:

\section{"Artículo 483.-}

El obligado a prestar alimentos puede pedir que se le exonere si disminuyen sus ingresos, de modo que no pueda atenderla sin poner en peligro su propia subsistencia, o si ha desaparecido en el alimentista el estado de necesidad.

Tratándose de hijos menores, a quienes el padre o la madre estuviese pasando una pensión alimenticia por resolución judicial, ésta deja de regir al llegar aquellos a la mayoría de edad.

Sin embargo, si subsiste el estado de necesidad por causas de incapacidad física o mental debidamente comprobadas o el alimentista está siguiendo una profesión u oficio exitosamente, pude pedir que la obligación continúe vigente."

El citado artículo se contempla la posibilidad del cese provisional de la obligación, siempre y cuando falte uno de los requisitos objetivos, o lo que es lo mismo, si la fortuna del alimentante disminuyera o si la nueva situación del alimentista le permitiera mantenerse por sí mismo; sin embargo, como indica la doctora Claudia Morán (2003), ello no implica que el derecho a percibir la pensión alimentaria no se extinguió. Ello se respalda también en lo establecido en la resolución recaída en el Expediente No. 2476-95-Ejecutorias:

El obligado a prestar alimentos puede pedir que se le exonere de seguir prestándolos si disminuyen sus ingresos, de modo que no pueda atender a la obligación sin poner en peligro su propia subsistencia.

Procede la exoneración, ya que nadie puede obligar al alimentante a que deje sus necesidades básicas de subsistencia por darle a otro lo que necesite (Canales 2013, 70).

Todo lo mencionado parte del principio de proporcionalidad que se establece para determinar la pensión alimentaria en virtud a los ingresos del alimentante, debido a que la finalidad de los alimentos como tal, no es para enriquecer a quien le corresponde, sino para cubrir las necesidades básicas del menor, primando en todo momento el interés superior del niño.

Respecto a las características del monto de la pensión, como menciona la doctora Claudia Canales Torres, el monto es la manifestación concreta de la obligación alimentaria y en esencia el artículo 481 del Código Civil establece una regla general: la cuantía de los alimentos se fija por el juez teniendo en cuenta la necesidad del que los

(3) El autor indica que, en virtud a lo establecido en la norma procesal, la variación de la pensión alimenticia entrará en vigencia a partir del día siguiente de la notificación de la demanda de aumento. 
pide y la posibilidad de quien los presta. Los alimentos que se deben por regla general son los congruos; es decir, los que sean compatibles con la condición de las partes.

Adicionalmente, debe tenerse en consideración que la base del cálculo para fijar la pensión alimentaria comprende todos los ingresos del deudor alimentista, pues toda suma ganada es un ingreso que debe ser compartido con quien dependa del obligado alimentista.

Esta breve explicación de la teoría de los alimentos nos puede llevar a solucionar situaciones en las cuales se presentan supuestos de capacidad económica en el deudor alimentista, y lamentablemente en sede penal se ha venido criminalizando los incumplimientos en el pago de las pensiones de manera general disponiendo inicio de investigaciones preliminares y futuros procesos penales por delito de omisión a la asistencia familia, cuando a nivel de derecho civil si existen supuestos en los cuales el deudor alimentista presenta situaciones que menguan su capacidad económica, lo cual debe ser considerado como elemento del tipo penal que pasaremos a analizar en el siguiente acápite.

\section{Sobre el delito de omisión a la asistencia familiar}

El delito de incumplimiento de obligación alimentaria se encuentra tipificado en el artículo 149 del Código Penal de la siguiente manera:

"El que omite cumplir su obligación de prestar los alimentos que establece una resolución judicial, será reprimido con pena privativa de libertad no mayor de tres años, o con prestación de servicio comunitario de veinte a cincuenta y dos jornadas, sin perjuicio de cumplir el mandato judicial (...)".

Cabe precisar que en este delito el bien jurídico protegido es el deber de asistencia, auxilio o socorro que tienen los componentes de una familia entre sí. Este deber se entiende como la obligación que se tiene de los requerimientos económicos que sirvan para satisfacer las necesidades básicas de supervivencia de determinados miembros de su familia (Salinas 2008, 408).

En la misma línea argumentativa, Peña Cabrera (2011, 448) señala que el tipo penal del artículo 149 del Código penal tendría como objeto de protección, la integridad y bienestar de la familia, cuando el sujeto obligado no satisface por entero, las necesidades más elementales de sus miembros, en otras palabras, el deber de asistencia familiar (Donna 2001, 431).
La ley exige que este incumplimiento no esté referido no sólo a la falta de asistencia material o económica, sino también a la de carácter moral, como son las obligaciones de auxilio mutuo, educación, cuidado de la prole, etc.

Ahora bien, corresponde hacer una precisión respecto al principio "no hay prisión por deudas", el mismo que encuentra reconocimiento constitucional bajo el literal c, inciso 24 del artículo 2 de la Constitución Política del Perú(4). Ante de ello, debe entenderse el delito de omisión a la asistencia familiar resulta una excepción a este principio, en razón que el legislador habría realizado una ponderación entre el principio de prohibición de prisión por deudas y el interés superior del niño, inclinándose más por esta última y siendo este el fundamento del delito analizado.

El tipo penal exige para su configuración que el autor del delito omita cumplir una resolución judicial, siendo que este término comprende tanto una sentencia como un auto de asignación provisional de alimentos que se fija en el inicio del proceso o inmediatamente de iniciado, a favor del beneficiario (Donna 2001, 404).

Asimismo, es de resaltar que el tipo penal hace alusión al sujeto obligado, con lo cual podemos concluir que nos encontramos ante un delito especial propio, o de infracción de deber. Al respecto, el profesor Felipe Villavicencio señala que en los delitos especiales o de infracción de deber propios, la lesión del deber especial fundamenta la punibilidad (Villavicencio 206, 306). Es evidente que el delito analizado sólo puede ser cometido por un sujeto especial, no siendo uno de tipo común, cuyo ámbito de comisión recae en cualquier persona.

De acuerdo a lo indicado en el artículo 474 del Código Civil(5), los sujetos que pueden ser considerados obligados en una relación alimentaria son los cónyuges, los ascendientes, descendientes y los hermanos. También se contempla como obligado a

(4) Artículo 2.- Toda persona tiene derecho:

24. No hay prisión por deudas. Este principio no limita el mandato judicial por incumplimiento de deberes alimentarios.

(5) Artículo 474.- Se deben alimentos recíprocamente: 1.- Los cónyuges. 2.- Los ascendientes y descendientes. 3.- Los hermanos. 
las personas que han asumido la patria potestad sin ser directamente los padres.

Ahora bien, con relación a la tipicidad objetiva de este delito, aquel se configura cuando el agente dolosamente omite cumplir su obligación de prestar alimentos, establecido previamente en una resolución judicial como pensión alimenticia concluido el proceso civil de alimentos. Es decir, el delito se configura cuando el sujeto obligado a pesar de tener conocimiento de la resolución judicial que obliga a la prestación de alimentos, éste la omite dolosamente.

En sede nacional, el profesor Ramiro Salinas Siccha señala que: "basta que se omita cumplir la resolución judicial debidamente emitida y puesta en su conocimiento al agente, para estar ante una conducta delictiva" $(2008,409)$. Asimismo, a nivel jurisprudencial, se emitió la Ejecutoria Superior recaída en el Expediente No. 26-12-2000, del 27.09.2000, Sala Penal de Apelaciones de la Corte Superior de Justicia de Lima, en la que se establece lo siguiente:

"El comportamiento punible en esta clase de ilícitos es el de omitir la observancia de la prestación de alimentos ordenada por resolución judicial, teniendo en consideración que el bien jurídico es la familia y específicamente los deberes de tipo asistencial, como obligación de los padres con sus descendientes, de acuerdo a lo previsto en el Código de los niños y los adolescentes".

Pues bien, somos de la opinión que para una adecuada integración del tipo penal el concepto de alimentos debe ser definido como lo indispensable para el sustento, habitación, vestido, asistencia familiar educación, capacitación para el trabajo, salud y recreación según la situación y posibilidades de la familia.

En ese sentido, el concepto jurídico de alimento comprende "todo aquello que una persona tiene derecho a percibir de otra por ley, declaración judicial o convenio, para atender a su, subsistencia, habitación, vestido, asistencia médica, educación e instrucción"(6). Su carencia se constituye en el incumplimiento del derecho alimentario. Adicionalmente, debemos indicar que el delito de omisión a la asistencia familiar es considerado como uno de peligro, en la medida que basta con dejar de cumplir con la obligación para realizar el tipo, sin que sea necesario que debido a tal incumplimiento se cause un perjuicio a la salud del sujeto pasivo, requiriéndose que dicho comportamiento se realice necesariamente a título de dolo.

Respecto a este punto, Villa Stein señala que: "la conducta que exige el tipo es la omisiva de no prestar los alimentos conforme lo ordena una resolución judicial, poniendo en peligro la satisfacción de necesidades básicas del necesitado. Es pues un delito de peligro( ${ }^{(7)}$. Al respecto, la jurisprudencia nacional se ha pronunciado de la siguiente manera:

"1. Naturaleza. Conforme a la redacción del artículo 149 del Código penal, el delito de omisión de asistencia familiar se configura cuando el agente omite cumplir con la prestación de alimentos establecida por resolución judicial, razón por la que se dice que es un delito de peligro, en la medida que basta con dejar de cumplir con la obligación para realizar el tipo, sin que sea necesario que debido a tal incumplimiento se cause un perjuicio a la salud del sujeto pasivo, requiriéndose que dicho comportamiento se realice necesariamente a título de dolo"(8).

Del mismo modo, la Ejecutoria Superior recaída en el Expediente No. 7270-1997 señala que "uno de los requisitos para abrir instrucción en este tipo de delitos es que el demandado haya sido notificado con el requerimiento de ley en su domicilio real y legal" (énfasis agregado).

Asimismo, es menester señalar que el presente tipo penal no exige la omisión de cumplimiento de una cantidad mínima de pensiones alimentarias mensuales establecidas en una resolución judicial, sino que, como se desprende de la Ejecutoria Suprema recaída en el Expediente No. 601998, "El comportamiento en el ilícito instruido consiste en omitir el cumplimiento de la prestación de alimentos establecida por una resolución judicial. Es decir, basta con dejar de cumplir con la obligación para realizar el tipo penal, teniendo en consideración que el bien jurídico protegido es la familia y especialmente los deberes de tipo asistencial" (énfasis agregado). En consecuencia, para la comisión del delito de omisión de asistencia familiar basta con omitir una sola pensión alimentaria mensual para que se consuma el delito (énfasis agregado).

De otro lado, consideramos que el delito de omisión a la asistencia familiar es uno de

(6) Enciclopedia Jurídica Omeba, 1986, p. 645.

(7) Javier Villa Stein, ob, cit., p. 96.

(8) Ejecutoria Superior recaída en el Expediente No. 6806-1997, del 01.07.1999, Primera Sala Penal para reos libres de la Corte Superior de Lima, citada en Caro $(2007,427)$. 
naturaleza instantánea, pero de efectos permanentes, por cuanto se da la consumación en el momento que el agente incumple con el pago de las pensiones devengadas al ser requerido por el Juzgado Civil dentro del plazo de tres días, bajo apercibimiento expreso de ser denunciado por el delito indicado.

Ahora bien, la posición que hoy exponemos para su análisis, relacionado a la capacidad económica del obligado como elemento de la configuración del tipo penal, consideramos que la misma tiene respaldo en lo señalado en el Acuerdo Plenario No. 02-2016/ClJ-116, en el que expresamente describe que el delito de omisión a la asistencia familiar, por su propia configuración típica exige no solo la obligación legal del imputado, la entidad del monto mensual de la pensión de alimentos y del objetivo incumplimiento del pago, previo apercibimiento, por el deudor alimentario. Sino también, necesariamente la posibilidad de actuar, pues lo que se pena no es el no poder cumplir, sino el no querer cumplir; es la consecuencia de la cláusula general de salvaguarda propia de los comportamientos omisivos, según la cual se comete un delito de dicha estructura.

Como hemos señalado, los delitos de omisión propia presentan tres elementos distintivos: (i) situación típica generadora del deber, (ii) no realización de la conducta ordenada y (iii) posibilidad psicofísica del individuo para ejecutar la acción ordenada. Es así que, la tipicidad en el delito omisivo es una operación inversa a la del delito de comisión, puesto que en el de comisión debe subsumirse la conducta realizada en la descrita por el tipo, mientras que en el delito de omisión la tipicidad se comprueba demostrando que la conducta realizada no se subsume en la descripción de la acción ordenada. Por consiguiente, somos de la opinión que la capacidad de pago es un elemento que debe dilucidarse en sede penal, aunado a los requisitos de tipicidad objetiva:

- Mandato de un pago de alimentos (sentencia civil o auto provisional),

- Requerimiento de pago,

- No cumplimiento del requerimiento

Siendo ello así, podemos concluir que los elementos del delito de omisión a la asistencia familiar guardan estrecha similitud con el tipo penal de desobediencia y resistencia a la autoridad previsto en el artículo 368 del Código penal. En dicho tipo penal, la desobediencia es la rebeldía u oposición abierta, hostil y maliciosa, acompañada de actos de contradicción, decidida y resuelta al cumplimiento de un mandato u orden en curso de ejecución, expreso y personal de la autoridad en ejercicio de sus funciones ${ }^{(9)}$.

A su vez, Peña Cabrera también sostiene que la orden debe ser notificada debidamente, señalando lo siguiente:
"La resolución administrativa o la resolución jurisdiccional, para que sean exigibles al destinatario, deben observar ciertos requisitos formales; no se puede obligar al administrado si es que la orden impartida, no ha sido debidamente notificada al destinatario, para la ejecución de la orden se requiere de que el afectado con la medida tome conocimiento oportuno. Lo que da a lugar, a lo que cierto sector de la doctrina alude como la conminación previa" (énfasis agregado) (Peña Cabrera 2011, 145).

Por tanto, como se ha indicado, la doctrina nacional (Abanto 2003, 170-173; San Martín 1988) ha señalado que en la orden deba existir una conminación previa, de modo que su incumplimiento recién puede configurar la acción típica del delito de desobediencia a la autoridad. Así, por ejemplo, el profesor Manuel Abanto Vásquez (2003, 172), de la mano con la jurisprudencia, señala que:

"Como correctamente lo ha establecido la jurisprudencia nacional, debe existir una conminación previa en una resolución y otra que haga efectivo el apercibimiento previo" (énfasis agregado).

En tal sentido, para que se configure la acción prevista en la descripción legal del delito de desobediencia a la autoridad, resulta indispensable que la orden incumplida haya sido previamente conminada, es decir, requerida bajo apercibimiento de ser denunciado por delito de resistencia o desobediencia a la Autoridad.

Asimismo, en la Ejecutoria Suprema recaída en la Casación No. 50-2017-Piura, de fecha 10 de abril de 2018, emitida recientemente por la Sala Penal Permanente de la Corte Suprema, se reitera que es necesaria la posibilidad de cumplir el mandato. En tal sentido, la Corte Suprema indica lo siguiente:

"SEXTO. Que, ahora bien, el delito de desobediencia a la autoridad, previsto y sancionado en el artículo 368, primer párrafo, del Código Penal, reprime con una pena privativa de libertad no menor de seis meses ni mayor de dos años, al

(9) Expediente No. 922.81-Cajamarca, del 16 de octubre de 2016. Sala Penal, citado en Caro (2017, 631). 
que "...desobedece [...] la orden legalmente impartida por un funcionario público en el ejercicio de sus atribuciones, salvo que se trate de la propia detención...". Es claro que la orden o mandato -judicial en este caso- debe ser expreso, escrito en este caso -incluso puede ser verbal- y sin imprecisiones o vaguedades -claro y concreto-; además, debe estar dirigido a una persona o autoridad determinada -lo que importa un requerimiento válido, del que se haya tenido conocimiento a su debido tiempo-y, en lo específico, con capacidad para cumplirla-de posible realización-. Se trata, además, de un delito doloso; $y$, como tal, es esencial que el sujeto activo, respecto de lo ordenado, tenga un deber de actuación y que su incumplimiento no se deba a una imposibilidad material de hacerlo (Ejecutoria Suprema RN No. 1337-2013/Cusco, 20 de enero de 2015).

SÉPTIMO. Que el deber de actuación del funcionario público concernido tiene límites objetivos, no solo en su propio control de la Administración para cumplir la orden judicial - capacidad para dictar órdenes y garantizar la ejecución del mandato judicial-, sino, cuando se trata de recursos públicos, en el respeto a las regulaciones del Derecho Presupuestario. La gestión de los recursos públicos está rigurosamente normativizado, por el cumplimiento de un pago determinado está sujeto a lo que el ordenamiento prevé y a las gestiones que sobre el particular deban hacer las autoridades competentes. La criminalidad de una desobediencia objetiva al mandato judicial reside en que el agente público, pese a conocer el mandato judicial y poder cumplir con sus directivas -facultades legales y el tiempo razonable para acatarlo-, no lo hace. Con esta finalidad, debe examinarse cuidadosamente las atribuciones y funciones del agente público concernido, así como tratándose de fondos públicos- la factibilidad material de su cumplimiento en atención al Derecho administrativo y presupuestario. No se puede exigir lo imposible, ni que se destinen fondos públicos sin la correspondiente autorización legal. Un mandato judicial de pago de remuneraciones exige su debido cumplimiento pero condicionado a lo anterior. EI funcionario público no decide libérrimamente sobre fondos públicos $\mathrm{y}$, menos, el desobedecimiento de un mandato judicial puede estimarse delictivo si, al tiempo de su emisión, las reglas presupuestales no lo permiten. La calificación de delictivo de un incumplimiento de un mandato judicial por el solo transcurrir del tiempo no resulta razonable.

OCTAVO. Que la intencionalidad en el incumplimiento no se deduce del hecho de que el funcionario público no comunicó a tiempo la imposibilidad de pago a la autoridad judicial que dictó el mandato. No es un problema de comunicación de la imposibilidad de pago, sino de la propia imposibilidad de hacerlo según los baremos ya indicados. Podrá ser un indicio esa inmediata omisión de justificación, pero no es suficiente para inferir que, por ello, se cometió el delito en análisis" (énfasis agregado).

En efecto, como podemos advertir, el delito de omisión de asistencia familiar presupone los elementos típicos del delito de resistencia a la autoridad, los cuales deben presentarse en el desarrollo del proceso civil, en el que a pesar de existir el requerimiento de cumplimiento del derecho alimentario, es incumplido por el demandado de forma dolosa.

Ahora bien, ponemos en consideración el supuesto en el cual el sujeto obligado a prestar alimentos sufre un accidente de gravedad que impide el cumplimiento de su obligación preestablecida por el ordenamiento civil. En tal caso, es evidente que la persona no podrá cumplir con lo ordenado en dicha sede, generando con su incumplimiento un aparente delito de omisión a la asistencia familiar; sin embargo, la capacidad económica es un elemento que sí puede ser analizado desde la tipicidad objetiva y subjetiva del delito.

Un caso similar ocurrió en Arequipa, en el cual la Sala Penal de Apelaciones ${ }^{(10)}$ confirmó una sentencia absolutoria por delito de omisión de asistencia familiar, proceso penal en el cual se cuestionó la capacidad de pago como elemento del tipo penal, señalándose lo siguiente:

"2.3. Entonces, debe verificarse la capacidad de pago (Posibilidad psicofísica del individuo para ejecutar la acción ordenada). Si bien está acreditada objetivamente: i) el mandato de un pago de alimentos [sentencia civil de alimentos de fecha diez de octubre del dos mil siete], ii) el requerimiento de pago [resolución No. 81-2014, de fecha 01 de diciembre del 2014], iii) el no cumplimiento del requerimiento [remisión de copias al Ministerio Público con fecha 16 de enero del 2016]; sin embargo, la defensa precisa que la incapacidad adquirida por su representado viene ya desde el

(10) Sentencia de la Tercera Sala Penal de Apelaciones recaída en el Expediente No. 02945-2016-24-0401-JR-PE-01, de fecha 23 de agosto de 2017. 
quince de julio del dos mil cuatro, pues sufrió un accidente generándole una discapacidad del $70 \%$ de carácter permanente, producto de un desbarranco que sufrió en el puente de Fierro, en el que tuvo fractura expuesta de base de cráneo, desgarro de hígado, fracturas intercostales, entre otras fracturas graves, además de un trastorno cognitivo con un menoscabo del $70 \%$; por lo que a la fecha del requerimiento de pago el 01 de diciembre del dos mil catorce, su patrocinado ya se encontraba en la imposibilidad de ejecutar la acción ordenada. Fundamentos por los que concordamos con el razonamiento del A quo."

En este caso, el obligado alimentario planteó la imposibilidad del pago de la pensión en sede civil, alegando que desde antes del requerimiento de pago, éste sufrió un accidente generándole una discapacidad del $70 \%$ de carácter permanente, producto de un desbarranco que sufrió en el puente de Fierro, en el que tuvo fractura expuesta de base de cráneo, desgarro de hígado, fracturas intercostales, entre otras fracturas graves, además de un trastorno cognitivo con un menoscabo del $70 \%$; por lo que a la fecha del requerimiento de pago el 01 de diciembre de 2014, no podía cumplir con la acción ordenada por la jurisdicción civil.

Somos de la opinión que en sede penal sí podría probarse la capacidad económica del sujeto obligado para dar cumplimiento a lo ordenado por el Juzgado Civil o de Familia como sustento de una defensa de atipicidad de la conducta atribuida como delito de omisión a la asistencia familiar, caso contrario, la investigación y proceso penal sería una mera formalidad, por cuanto la sanción penal se daría de manera automática ante el incumplimiento del mandato civil.

Pues bien, si consideramos la falta de capacidad económica como un elemento del tipo objetivo, su falta de concurrencia conllevaría a la aticipidad objetiva del delito. Concordante con lo expuesto, si la capacidad económica la asumimos como elemento de la tipicidad objetiva, de modo que para que pueda hablarse de una verdadera substracción al deber de asistencia, es necesario que el sujeto activo esté en condiciones de satisfacer el deber jurídico, es decir que tenga poder económico.

De otro lado existe una corriente que considera a la imposibilidad material de cumplir con la obligación alimentaria como un elemento a analizarse en la tipicidad subjetiva. Así, se afirma que si el agente conoce la situación típica y también el hecho de la omisión, pero carece de poder de hecho, por ejemplo se halla en estado de indigencia total, el dolo estará ausente por falta de representación, le ha sido imposible reconocer el camino, no obstante su conocimiento de la situación típica, pues el conocimiento abarca tanto la posibilidad de representarse la conducta ordenada como los caminos tendientes a evitar el resultado típico. Cabe distinguir este supuesto del de ausencia de conocimiento de la posibilidad de cumplir con el mandato de acción, anteriormente mencionado, que sí conduce a un error de tipo excluyente del dolo.

A nivel nacional, el profesor César Nakasaki, en un evento convocado por el Poder Judicial, señaló que se observa un diminuto trabajo probatorio por parte del Ministerio Público en los procesos penales por delito de omisión de asistencia familiar, por cuanto erróneamente se conceptúa que el hecho que sea una sentencia la que determine la obligación de alimentos, las necesidades del alimentista, la capacidad del alimentante y la cuota de alimentos, configura una licencia para ya no seguir desplegando actividad probatoria, como por ejemplo probar la capacidad económica del obligado.

Aparentemente, esta posición estaría regulada en el artículo 481 del Código Civil(11) que se convierte en una excepción a la regla de la certeza que rige en la teoría de la prueba; la norma legal citada, expresamente declara que basta la probabilidad para fijar la capacidad económica del alimentante. Tal excepción, explicable en el derecho civil por la función tuitiva de la figura de los alimentos, no tiene cabida en el campo penal, donde la certeza es el grado de conocimiento indispensable para fijar un hecho como relevante, al emitir sentencia condenatoria; máxime si se tiene en cuenta que la capacidad económica del alimentante es un elemento del tipo penal de incumplimiento de la obligación alimentaria; capacidad individual de acción. El tema de la prueba son todos los elementos del tipo penal del artículo 149 del Código Penal, correspondiendo al juez penal un deber de indagación más profundo que el que tocó al juez civil.

(11) Artículo 481.- Criterios para fijar alimentos

Los alimentos se regulan por el juez en proporción a las necesidades de quien los pide y a las posibilidades del que debe darlos, atendiendo además a las circunstancias personales de ambos, especialmente a las obligaciones que se halle sujeto el deudor. El juez considera como un aporte económico el trabajo doméstico no remunerado realizado por alguno de los obligados para el cuidado y desarrollo del alimentista, de acuerdo a lo señalado en el párrafo precedente. No es necesario investigar rigurosamente el monto de los ingresos del que debe prestar los alimentos. 
Ahora bien, surge una última interrogante respecto a la valoración que debe hacer el juez penal cuando una persona ya ha sido condenada por un período de deuda alimentaria incumplida y se esta se encuentra dentro de un segundo proceso penal por otro período distinto, ¿debe valorar el juez penal de este segundo proceso la condición jurídica del condenado?

Frente a este problema planteado la respuesta será abordada desde lo desarrollado en el presente artículo. Así, sostenemos que el juez del segundo proceso penal deberá necesariamente evaluar la condición económica e intención de cumplir del condenado. Nos explicamos.

Respecto a la capacidad económica, este elemento como se desarrolló anteriormente debe ser valorado por el juez ya que la posibilidad -en este caso económica- de cumplir del agente reviste un elemento objetivo del tipo al igual que el delito de resistencia y desobediencia a la autoridad, pues no se puede pretender exigir una conducta que el agente no es capaz de realizar. Ahora bien respecto a la intención de cumplimiento del sujeto debe evaluarse la disposición del mismo, es decir, en el caso planteado bien podría ser que el condenado cuenta con bienes a su nombre pero en su condición de preso no puede disponer libremente de sus bienes, en virtud de ello resultaría abusivo que el juez del segundo proceso penal emita una sentencia condenatoria a un condenando que cuenta con bienes pero no los puede disponer.

Así, para evitar problemas como los anteriores y cargar innecesariamente a los jueces penales con evaluar la capacidad económica del agente, consideramos que el juez civil será a quien le corresponde evaluar la capacidad económica del agente antes de remitirlo a una vía penal, pues como toda denuncia penal la ley exige un nivel de convicción mínimo para que esta prospere y avance en las etapas del proceso. Siendo ello así, el Ministerio Público debería exigir que la denuncia demuestre la capacidad económica del denunciado cuando incumplió la obligación, si este es insolvente corresponderá archivar la denuncia y evitar mayor carga procesal.

Finalmente, debemos notar que la propuesta defendida en el presente artículo actualmente no ha sido tomada en cuenta por la judicatura; sin embargo, debemos hacer mención a un caso en particular sometido a la jurisdicción del Segundo Juzgado Unipersonal de Ventanilla donde se ha señalado lo siguiente:

“(...) la conducta típica no se refleja únicamente en el incumplimiento propiamente dicho, sino que a criterio de esta judicatura es un requisito primordial para determinar la responsabilidad que el acusado haya tenido la posibilidad de cumplir, y no lo haya querido hacer"(12).

\section{Conclusiones}

1. La teoría de los alimentos tiene regulación expresa en el ordenamiento civil, estableciéndose el orden de prelación de los obligados al cumplimiento de la prestación en favor del alimentista, teniendo en consideración el principio de interés superior del niño.

2. El tipo penal de omisión de asistencia familiar debe ser analizado de manera sistemática, no pudiendo comprenderse al mismo como una modalidad agravada del delito de resistencia a la autoridad,

3. La capacidad económica del obligado alimentario es un elemento que puede invocarse como parte de la tipicidad objetiva del tipo penal, con lo cual ante la imposibilidad material de cumplir el mandato judicial que obliga a la prestación alimentaria, el tipo penal no se configuraría.

4. La capacidad económica del obligado alimentario debe ser probada en el proceso penal, caso contrario, se convierte el mismo en un mero método de criminalización de deudas.

5. La capacidad económica del obligado podría incluso ser materia de análisis del Ministerio Público en sede preliminar, no siendo atendible que dicho criterio sea valorado exclusivamente por el juez al momento de emitir sentencia en sede penal frente a una imputación fiscal por omisión de asistencia familiar, por cuanto en sede fiscal también se pueden actuar medios de investigación destinados a determinar la comisión o no de un tipo penal.

\section{Referencias bibliográficas}

Abanto Vásquez, Manuel. 2003. Los delitos contra la Administración Pública en el Código Penal peruano. Lima: Palestra Editores.

(12) Expediente No. 1092-2018-1-3301-JR-PE-01. Segundo Juzgado Penal Unipersonal - Sede NCPP, fundamento octavo. 
¿Debe tenerse en cuenta la capacidad económica del sujeto obligado en la tipicidad del delito de omisión a la asistencia familiar?

Should the economic capacity of the debtor be taken into account in the prosecution of the crime of omission of family assistance?

Canales Torres, Claudia. 2013. Criterios en la determinación de la pensión de alimentos en la jurisprudencia. Lima: Gaceta Jurídica.

Caro John, José Antonio. 2007. Diccionario de Jurisprudencia Penal. Lima: Grijley.

\& Thesis.

2017. Summa Penal. Lima: Nomos

Chávez Montoya, María Susan. 2017. La determinación de las pensiones de alimentos y los sistemas orientadores de cálculo. Tesis para optar por el título de abogado, Universidad Ricardo Palma.

Chunga Chávez, Carmen. 2003. Código Civil Comentado. Lima: Gaceta Jurídica.

Donna, Edgardo. 2001. Derecho Penal. Parte Especial, Tomo II-A. Buenos Aires: RubinzalCulzoni.
Hernández Alarcón, Christian. 2003. comentarista, Código Civil Comentado. Lima: Gaceta Jurídica.

Morán Morales, Claudia. 2003. Código Civil Comentado. Lima: Gaceta Jurídica.

Peña Cabrera, Raúl. 2011. Derecho Penal. Parte Especial. Tomo V. Lima: Idemsa.

Reyna Alfaro, Luis Miguel. 2007. Delitos contra la familia y violencia doméstica. Lima: Jurista Editores.

Salinas Siccha, Ramiro. 2008. Derecho Penal: Parte Especial. Lima: Grijley y lustitia.

San Martín Castro, César. 1988. Delito de Desobediencia a la autoridad. Anuario de Derecho Penal 1.

http://perso.unifr.ch/derechopenal/assets/files/anuario/ an_1988_07.pdf

Villavicencio Terreros, Felipe. 2006. Derecho Penal. Parte Especial. Lima: Grijley.

\section{Rebaza, Alcázan \& De Las Casas}

Fusiones y Adquisiciones

Reestructuración y Quiebras

Financiamientos

Mercado de Capitales

Proyectos e Infraestructura

Inversión Exranjera

Asesoría Corporativa

Planificación Tributaria
Planificación Laboral

White Collar Crime

Litigios Corporativos

Arbitraje

Private Clients

Venture Capital

Compliance

Perú Client Service Award 2016 - Chambers and Partners Awards for Excellence

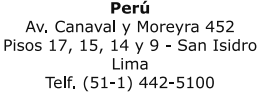

Av. Canaval y Moreyra 452
Pisos $17,15,14$ y 9 - San Isidr

Telf. (51-1) $442-510$
Chile

Oficina de representación Av. Apoquindo 3600 Piso 5 - Las Condes Santiago de Chile
Telf. (56-2) 2244-68432

www. rebaza-alcazar.com 